\title{
The enteric nervous system in inflammation and pain: The role of proteinase-activated receptors
}

\author{
Nathalie Vergnolle PhD
}

\begin{abstract}
$\mathrm{N}$ Vergnolle. The enteric nervous system in inflammation and pain: The role of proteinase-activated receptors. Can J Gastroenterol 2003;17(10):589-592.

The enteric nervous system (ENS) plays a pivotal role in inflammatory and nociceptive processes. Drugs that interact with the ENS have recently raised considerable interest because of their capacity to regulate numerous aspects of the gut physiology and pathophysiology. The present article summarizes recent research on proteinases and proteinaseactivated receptors (PARs) as signalling molecules in the ENS. In particular, experiments in animal models suggest that $\mathrm{PAR}_{2}$ is important to neurogenic inflammation in the intestine. Moreover, $\mathrm{PAR}_{2}$ agonists seem to induce intestinal hypersensitivity and hyperalgesic states, suggesting a role for this receptor in visceral pain perception. Thus, PARs, together with the proteinases that activate them, represent exciting new targets for therapeutic intervention on the ENS.
\end{abstract}

Key Words: Inflammation; Pain; Proteinases; Thrombin; Trypsin; Tryptase

\section{Le système nerveux entérique dans l'inflam- mation et la douleur : Le rôle des récepteurs activés par la protéinase}

Le système nerveux entérique (SNE) joue un rôle critique dans les processus inflammatoires et nociceptifs. Les médicaments qui interagissent avec le SNE ont récemment suscité un intérêt considérable en raison de leur capacité de réguler de nombreux aspects de la physiologie et la physiopathologie intestinales. Le présent article résume des recherches récentes sur les protéinases et les récepteurs activés par la protéinase (RAP) à titre de molécules de signalisation dans le SNE. En particulier, des expériences sur des modèles animaux laissent supposer que les $\mathrm{RAP}_{2}$ sont importants pour l'inflammation neurogène de l'intestin. De plus, les agonistes des $\mathrm{RAP}_{2}$ semblent induire une hypersensibilité intestinale et des états hyperalgésiques, ce qui laisse croire que ce récepteur joue un rôle dans la perception de la douleur viscérale. Cependant, les RAP, conjointement avec les protéinases qui les activent, représentent des nouvelles cibles intéressantes d'intervention thérapeutique sur le SNE.
$\mathrm{T}$ he gut is extensively innervated: the enteric nervous system (ENS) contains approximately $10^{8}$ neurons (as many as in the entire spinal cord). The ENS is characterized by an extensive and elaborate network of nerves extending from the esophagus to the anal sphincter. Intrinsic neurons have cell bodies within the submucous and myenteric plexuses, while the cell bodies of extrinsic sensory nerves are in the dorsal root ganglia of the spinal cord and in the nodose ganglia. The ENS controls motility, secretion, absorption, microcirculation, sensation and immune function in the gut. The present review focuses on the role of proteinases as signalling molecules for both the extrinsic and intrinsic nerves of the ENS, through the activation of proteinase-activated receptors (PARs).

\section{NEUROGENIC INFLAMMATION IN THE GUT}

The ENS modulates inflammatory processes in several distinct ways. One way is through the release of neuropeptides upon stimulation of enteric nerves by noxious agents. Intrinsic and extrinsic enteric nerves contain neuropeptides, such as substance $\mathrm{P}$, calcitonin gene-related peptide (CGRP) and vasoactive intestinal peptide (VIP), that modulate various components of the inflammatory process. The release of neuropeptides from both intrinsic and extrinsic enteric neurons can initiate neurogenic inflammation.
Vasodilation and increased vascular permeability are observed in response to CGRP and substance $\mathrm{P}$ release, through direct endothelial activation of the type I CGRP receptor and the neurokinin-1 receptor $(\mathrm{NK}-1)$, respectively. Activation of endothelial receptors for CGRP and NK-1 causes not only extravasation of plasma from the blood into the tissues, but also facilitates the recruitment of inflammatory cells (1) (Figure 1). Moreover, enteric neurons can stimulate mast cell degranulation by the release of substance P (Figure 1). Mast cell degranulation causes the release of numerous inflammatory mediators: cytokines, proteinases, nitric oxide and lipid mediators of inflammation, including prostaglandins, leukotrienes and thromboxane. Those molecules stimulate other inflammatory cells, such as macrophages, neutrophils and lymphocytes, which can then further promote the release of neuropeptides from enteric nerves, thereby amplifying the inflammatory response (Figure 1).

The ENS also influences vasodilation and vascular permeability indirectly, through the release of mast cell mediators (1). Because enteric neurons are closely associated with macrophages and lymphocytes in the gut wall, the release of VIP from those neurons seems to aggravate inflammation by stimulating cytokine release from $\mathrm{B}$ and $\mathrm{T}$ lymphocytes, as well as by increasing immunglobulin A synthesis by B-lymphocytes (1).

Department of Pharmacology and Therapeutics, University of Calgary, Calgary, Alberta.

Correspondence: Dr Nathalie Vergnolle, Department of Pharmacology and Therapeutics, University of Calgary, 3300 Hospital Drive Northwest,

Calgary, Alberta T2N 4N1. Telephone 403-220-4588, fax 403-210-8195, e-mail nvergnol@ucalgary.ca

Received for publication August 19, 2003. Accepted August 26, 2003 


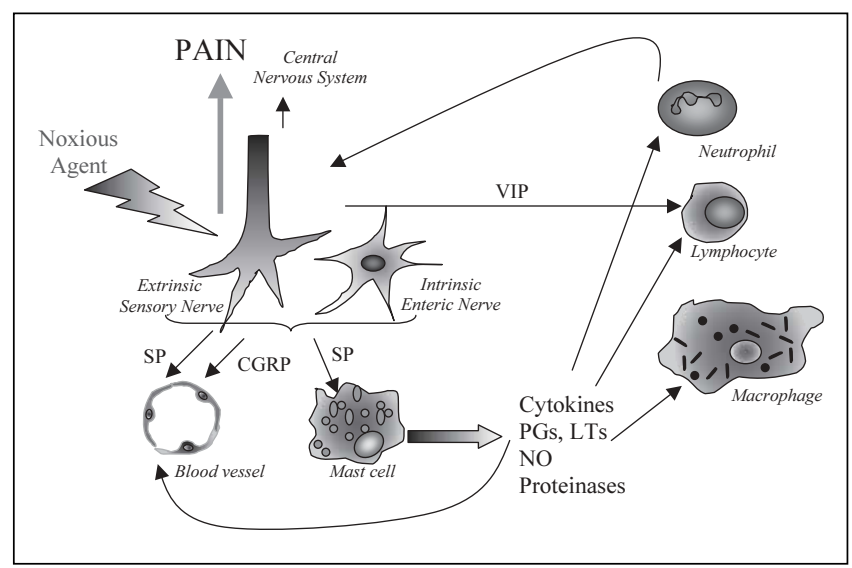

Figure 1) Interactions of the enteric nervous system (ENS) with components of the inflammatory process. Upon activation by noxious agents, the ENS (both extrinsic and intrinsic enteric nerves) release neuropeptides (substance P [SP] and calcitonin gene-related peptide [CGRP]) that, by acting on vascular endothelium, cause vasodilation and increased vascular permeability, two major features of the inflammatory reaction. Neuropeptides such as SP also provoke mast cell activation/degranulation, which subsequently activates the other actors of inflammation: vascular endothelium, macrophages, lymphocytes and neutrophils, through the release of various inflammatory mediators (cytokines, prostaglandins [PGs], leukotrienes [LTs], proteinases and nitric oxide [NO]). Inflammatory cells could, in turn, further induce the ENS to release neuropeptides, thus amplifying the inflammatory reaction. Through the release of vasoactive intestinal peptide (VIP), enteric neurons can also interact with inflammatory cells. Activation of nociceptive enteric neurons also conveys nociceptive information, especially pain, to the central nervous system

Thus, by releasing proinflammatory neuropeptides, the ENS is capable of initiating and amplifying inflammatory reactions. What could initiate a neurogenic mechanism of inflammation by triggering activation of the ENS and subsequent release of neuropeptides? We propose that PARs act as important mediators of ENS activation.

\section{PARS IN THE ENS}

PARs constitute a group of seven transmembrane $G$ proteincoupled receptors that are activated by the proteolytic cleavage of their $\mathrm{N}$-terminal domain. Proteolysis releases a new $\mathrm{N}$-terminal domain, which acts as a tethered ligand, binding and activating the receptor itself (2). Small synthetic peptides, corresponding to the tethered ligand domains released by proteolysis, are selective agonists for these receptors, and thus serve as useful pharmacological tools for understanding the physiology of these receptors. Three PARs $\left(\mathrm{PAR}_{1}, \mathrm{PAR}_{3}\right.$ and $\mathrm{PAR}_{4}$ ) are activated by thrombin, and have been cloned in the course of studies that aimed at understanding the role of thrombin in platelet activation (3). A fourth receptor $\left(\mathrm{PAR}_{2}\right)$ can be activated by trypsin and mast cell tryptase, as well as by pathogen proteinases, but not by thrombin $(2,4,5)$.

The four PARs are expressed throughout the gastrointestinal tract in different cell types (2). For example, immunoreactive $\mathrm{PAR}_{1}$ and $\mathrm{PAR}_{2}$ have been detected in more than $60 \%$ of neurons from the myenteric plexus of the guinea pig small intestine, both in primary cultures and in whole mounts of myenteric tissues (6). A large proportion of neurons expressing substance $\mathrm{P}$, a primary excitatory neuropeptide, also expressed $\mathrm{PAR}_{1}(89 \%)$ and $\mathrm{PAR}_{2}(50 \%)$. Similarly, a large percentage of neurons expressing VIP, which acts as an inhibitory motor transmitter, also expressed $\mathrm{PAR}_{1}$ (44\%) and $\mathrm{PAR}_{2}$ (90\%) $(6,7)$. More than $50 \%$ of neurons expressing $\mathrm{PAR}_{1}$ also expressed $\mathrm{PAR}_{2}$ (6).

$\mathrm{PAR}_{1}$ and $\mathrm{PAR}_{2}$ are also expressed by extrinsic enteric neurons. $\mathrm{PAR}_{2}$-like immunoreactivity and $\mathrm{PAR}_{2}$ mRNA expression have also been detected in rat isolated dorsal root ganglia neurons (8). Among the sensory neurons expressing $\mathrm{PAR}_{2}$, approximately $40 \%$ coexpressed CGRP and 30\% coexpressed substance $\mathrm{P}(8)$. $\mathrm{PAR}_{1}$ is also located in dorsal root ganglia neurons, where it often coexpressed with substance $P(9)$.

$\mathrm{PAR}_{1}$ and $\mathrm{PAR}_{2}$ are also functional in ENS cells. Linden and colleagues $(10)$ have shown that $\mathrm{PAR}_{2}$ agonists signal guinea pig myenteric neurons, inducing depolarization and increasing the number of action potentials in isolated cells. Reed and colleagues (7) have shown that $\mathrm{PAR}_{2}$ agonists evoked depolarization and long term excitation in submucosal neurons isolated from the guinea pig ileum. Both $\mathrm{PAR}_{1}$ and $\mathrm{PAR}_{2}$ agonists stimulate calcium mobilization in isolated guinea pig myenteric neurons (6) and dorsal root ganglia neurons $(8,9)$. Although the presence of $\mathrm{PAR}_{1}, \mathrm{PAR}_{2}$ and $\mathrm{PAR}_{4}$ was not clearly established, a study by Gao et al (11) suggested that those receptors act on neurons that regulate enteric motor function in the guinea pig small intestine.

This large expression of PARs strongly suggests that they play a crucial role in the physiology and pathophysiology of the ENS. Among the functions of the ENS, it appears that proteinases and PARs are especially likely to regulate inflammation and pain.

\section{PAR $_{2}$ TRIGGERS ENTERIC NERVES TO CAUSE INFLAMMATION}

It is known that all the hallmarks of inflammation - swelling, increased blood flow and granulocyte infiltration - are induced by exposure of various tissues (paw, airways, skin, etc) to $\mathrm{PAR}_{2}$ agonists (12-14). Because proteinases that are able to activate $\mathrm{PAR}_{2}$ (such as trypsin and mast cell tryptase) are particularly abundant in the gut of patients with inflammatory bowel diseases (IBD) (15-17), we hypothesized that high concentrations of proteinases in the lumen of the gut might induce intestinal inflammation. We have shown that, in the rat colon, the intracolonic injection of a selective $\mathrm{PAR}_{2}$ agonist $\left(\mathrm{PAR}_{2}\right.$-activating peptide), as well as of trypsin and mast cell tryptase, caused edema, granulocyte infiltration and intestinal barrier breakdown, as demonstrated by bacterial translocation from the gut to peripheral organs (18). Furthermore, we have shown that this $\mathrm{PAR}_{2}$ agonist-mediated colitis could be inhibited by a pretreatment with capsaicin, a neurotoxin that depletes sensory neurons of their neuropeptide content, or pretreatment with NK-1 or CGRP receptor antagonists (19). These results showed that the intestinal inflammation induced by $\mathrm{PAR}_{2}$ agonists is under neural control, and is affected by the release of neuropeptides such as substance $P$ and CGRP. The release of substance $\mathrm{P}$ and CGRP, as a direct result of activation of $\mathrm{PAR}_{2}$ on ENS neurons, was not demonstrated in this study. Evidence supporting this idea include the facts that functional $\mathrm{PAR}_{2}$ has been identified on ENS neurons that also expressed substance $\mathrm{P}$ and CGRP, and that isolated sensory afferents can release substance $\mathrm{P}$ and CGRP upon direct application of $\mathrm{PAR}_{2}$ agonists. 
Taken together, these results showed that, upon $\mathrm{PAR}_{2}$ activation, the ENS releases neuropeptides (substance $\mathrm{P}$ and CGRP) that initiate neurogenic inflammation, characterized by edema and granulocyte infiltration (19) (Figure 2).

An important step in understanding the role of $\mathrm{PAR}_{2}$ in the gut would be to investigate to what extent $\mathrm{PAR}_{2}$-induced ENS activation is associated with bowel disease. Because inflammation driven by enteric infections has been shown to be largely mediated by a neurogenic mechanism involving extrinsic sensory nerves, substance P and CGRP receptors (20), it could be hypothesized that pathogens release proteinases that activate $\mathrm{PAR}_{2}$ on enteric neurons, and that this activation leads to mucosal inflammation. This hypothesis is supported by the fact that $\mathrm{PAR}_{2}$ can be activated by proteinases from pathogens such as dust mites (5) or Porphyromonas gingivalis (4). $\mathrm{PAR}_{2}$ activation by pathogens would support a proinflammatory role for $\mathrm{PAR}_{2}$ in enteric infections and would suggest that $\mathrm{PAR}_{2}$ antagonists might be helpful in the treatment of enteric infections. In IBD models, however, activation of the ENS and further release of neuropeptides have been shown to be protective (21). Thus, in the setting of chronic intestinal inflammation, $\mathrm{PAR}_{2}$-induced ENS activation might have beneficial and protective effects. This hypothesis is further supported by the findings of Fiorucci and colleagues (22), who have observed that daily systemic treatment with a $\mathrm{PAR}_{2}$ agonist was protective in a model of trinitrobenzene sulfonic acid-induced colitis. The lack of readily available $\mathrm{PAR}_{2}$ antagonists has hampered progress in this field. The availability of $\mathrm{PAR}_{2}$-deficient mice should help, in the very near future, to clarify this hypothesis.

\section{DOES PAR 2 TRIGGER ENTERIC NERVES TO CAUSE VISCERAL HYPERSENSITIVITY?}

Afferent sensory fibres of the ENS not only release inflammatory neuropeptides, but they also convey sensory data. One hypothesis is that activation of PARs, and particularly $\mathrm{PAR}_{2}$, on enteric afferent sensory fibres might also send a nociceptive signal to the central nervous system. It has been shown that subinflammatory doses of $\mathrm{PAR}_{2}$ agonists $\left(\mathrm{PAR}_{2}\right.$-activating peptides but also trypsin and tryptase), when injected into the rat or mouse paw, provoked nociceptor activation at a spinal level, together with severe and prolonged hyperalgesia (23). Within $2 \mathrm{~h}$ after their intracolonic administration, $\mathrm{PAR}_{2}$ agonists $\left(\mathrm{PAR}_{2}\right.$-activating peptides and trypsin) also caused nociceptor activation at a spinal level, as demonstrated by increased fos protein expression in the superficial laminae of the spinal dorsal horn (24). Subinflammatory doses of $\mathrm{PAR}_{2}$ agonists from the colonic lumen provoked a significant increase in the number of abdominal contractions in response to rectal distension, which is characteristic of visceral hyperalgesia (24). Here again, these experiments could not unequivocally show that these pro-nociceptive and hyperalgesic effects of $\mathrm{PAR}_{2}$ agonists were due to a direct activation of $\mathrm{PAR}_{2}$ on the ENS. The study by Reed and colleagues (7), however, showed that transient exposure of enteric submucosal neurons to $\mathrm{PAR}_{2}$ agonists evoked long term hyperexcitability. Similar hyperexcitability of extrinsic afferent neurons could be responsible for the $\mathrm{PAR}_{2}$-induced hyperalgesia we observed in vivo in a rat model of visceral nociception (23).

Recent studies have shown that patients with the irritable bowel syndrome (IBS) exhibit an increased spontaneous release of mast cell tryptase from colonic tissues (25). It could

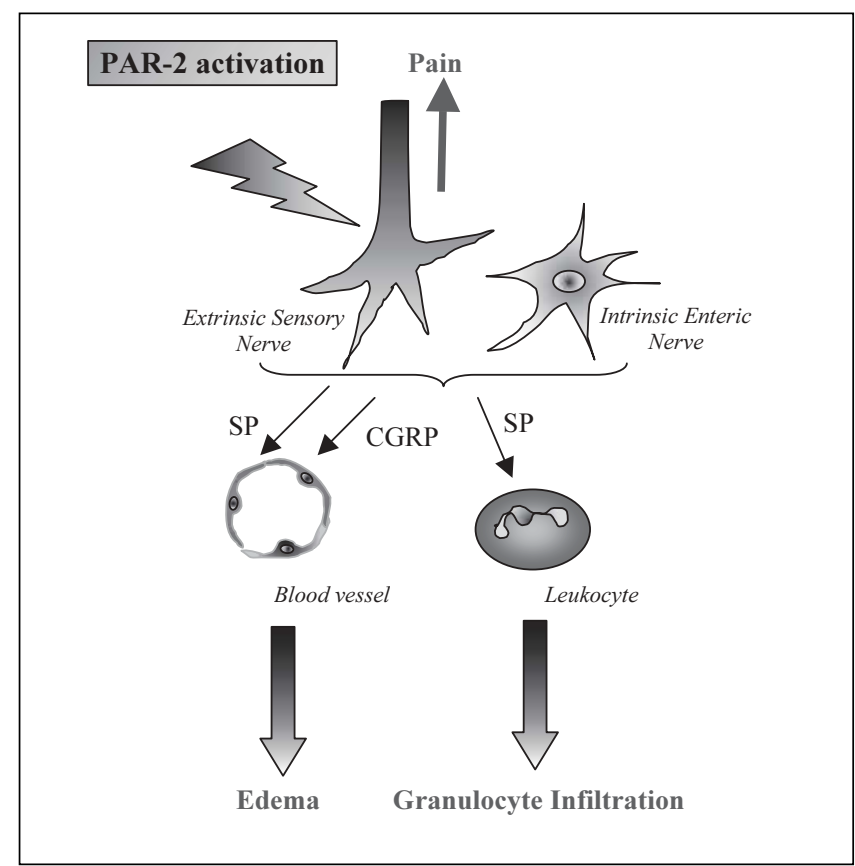

Figure 2) Proteinase-activated receptor-2 (PAR $)$ activation causes neurogenic inflammation in the mouse colon. Upon $P A R_{2}$ activation, the enteric nervous system releases substance $P(S P)$ and calcitonin gene-related peptide (CGRP), two proinflammatory neuropeptides, which induce increased vascular permeability and vasodilation, thereby causing edema. PAR 2 -induced SP release, through the activation of neurokinin-1 receptors, is involved in granulocyte recruitment

be hypothesized that tryptase-induced $\mathrm{PAR}_{2}$ activation of enteric sensory nerves induces a long term hyperexcitability of these neurons, resulting in the visceral pain and hyperalgesia experienced by IBS patients. Although a clear role for $\mathrm{PAR}_{2}$ activation has been demonstrated in the establishment of mast cell degranulation-induced somatic hyperalgesia, using $\mathrm{PAR}_{2}$ deficient mice (23), such a role in visceral hyperalgesia has yet to be demonstrated.

\section{THE ROLES OF OTHER PARS IN THE ENS}

Although a neurogenic mechanism involving NK-1 receptor activation has been demonstrated for $\mathrm{PAR}_{1}$ agonist-induced paw edema (9), there is currently no evidence that such a mechanism also occurs in the gut. Contrary to the situation with $\mathrm{PAR}_{2}$, subinflammatory doses of $\mathrm{PAR}_{1}$ agonists did not induce hyperalgesia after intraplantar injection, but they increased nociceptive threshold in rats and significantly inhibited inflammatory hyperalgesia induced by carrageenan (26). Here again, there is no evidence yet for such a mechanism in the gastrointestinal tract. However, other neurally controlled functions of the gut seem to be regulated by $\mathrm{PAR}_{1}$ activation on enteric neurons. Buresi and colleagues (27) have recently shown that $\mathrm{PAR}_{1}$ activation in mouse intestinal tissues, mounted in Ussing chambers, decreased secretory responses to neural stimulation. This suggests that $\mathrm{PAR}_{1}$ could contribute to disorders of secretory function associated with the development of colitis. It is interesting to note that $\mathrm{PAR}_{2}$ agonists also regulate intestinal secretion, but, unlike $\mathrm{PAR}_{1}, \mathrm{PAR}_{2}$ agonists have been shown to stimulate chloride secretion by a neuro- 
genic process (28). No studies have yet demonstrated a role for $\mathrm{PAR}_{3}$ or $\mathrm{PAR}_{4}$ in neurally evoked intestinal functions.

\section{CONCLUSIONS}

This review summarized recent evidence that proteinases, through the activation of PARs, are able to interact with the ENS, thereby affecting neurally evoked intestinal functions. Inflammation and pain perception appear to be two major functions that are regulated by neuronal PARs. There has been considerable interest recently in the development of agents that modify these processes. PARs that are expressed on nerves represent, together with the proteinases that activate them, exciting new targets for therapeutic intervention.

\section{REFERENCES}

1. Von Boyen GBT, Reinshagen M, Steinkamp M, Adler G, Kirsch J. Gut inflammation modulated by the enteric nervous system and neurotrophic factors. Scand J Gastroenterol 2002;37:621-5.

2. Vergnolle N. Review article: Proteinase-activated receptors - novel signals for gastrointestinal pathophysiology. Aliment Pharmacol Ther 2000;14:257-66.

3. Hollenberg MD, Compton SJ. International Union of Pharmacology. XXVIII. Proteinase-activated receptors. Pharmacol Rev 2002;54:203-17.

4. Lourbakos A, Potempa J, Travis J, et al. Arginine-specific protease from Porphyromonas gingivalis activates protease-activated receptors on human oral epithelial cells and induces interleukin-6 secretion. Infect Immun 2001;69:5121-30.

5. Sun G, Stacey MA, Schmidt M, Mori L, Mattoli S. Interaction of mite allergens Der $\mathrm{p} 3$ and Der $\mathrm{p} 9$ with protease-activated receptor-2 expressed by lung epithelial cells. J Immunol 2001;167:1014-21.

6. Corvera CU, Dery O, McConalogue K, et al. Thrombin and mast cell tryptase regulate guinea-pig myenteric neurons through proteinase-activated receptors-1 and -2. J Physiol (Lond) 1999;517:741-56.

7. Reed DE, Barajas-Lopez C, Cottrell G, et al. Mast cell tryptase and proteinase-activated receptor 2 induce hyperexcitability of guinea pig submucosal neurons. J Physiol 2003;547:531-42.

8. Steinhoff M, Vergnolle N, Young S, et al. Agonists of proteinaseactivated receptor 2 induce inflammation by a neurogenic mechanism. Nat Med 2000;6:151-8.

9. De Garavilla L, Vergnolle N, Young SH, et al. Agonists of proteinase-activated receptor 1 induce plasma extravasation by a neurogenic mechanism. Br J Pharmacol 2001;133:975-87.

10. Linden DR, Manning BP, Bunnett NW, Mawe GM. Agonists of proteinase-activated receptor 2 excite guinea pig ileal myenteric neurons. Eur J Pharmacol 2001;431:311-4.

11. Gao CY, Liu SM, Hu HZ, et al. Serine proteases excite myenteric neurons through protease-activated receptors in guinea pig small intestine. Gastroenterology 2002;123:1554-64.

12. Schmidlin F, Amadesi S, Dabbagh K, et al. Protease-activated receptor 2 mediates eosinophil infiltration and hyperreactivity in allergic inflammation of the airway. J Immunol 2002;169:5315-21.

13. Vergnolle N. Proteinase-activated receptor-2-activating peptides induce leukocyte rolling, adhesion, and extravasation in vivo. J Immunol 1999;163:5064-9.

14. Vergnolle N, Hollenberg MD, Sharkey KA, Wallace JL. Characterization of the inflammatory response to proteinaseactivated receptor-2 (PAR-2)-activating peptides in the rat paw. Br J Pharmacol 1999;127:1083-90.

15. Bustos D, Negri G, De Paula JA, et al. Colonic proteinases: Increased activity in patients with ulcerative colitis. Medicina (Buenos Aires) 1998;58:262-4.

16. Playford RJ, Hanby AM, Patel K, Calam J. Influence of inflammatory bowel disease on the distribution and concentration of pancreatic secretory trypsin inhibitor within the colon. Am J Pathol 1995;146:310-6.

17. Raithel M, Winterkamp S, Pacurar A, Ulrich P, Hochberger J, Hahn EG. Release of mast cell tryptase from human colorectal mucosa in inflammatory bowel disease. Scand J Gastroenterol 2001;36:174-9.

18. Cenac N, Coelho A, Nguyen C, et al. Induction of intestinal inflammation in mouse by activation of proteinase-activated receptor-2. Am J Pathol 2002;161:1903-15.

19. Nguyen C, Coelho A, Grady E, et al. Colitis induced by proteinase-activated receptor -2 agonists is mediated by a neurogenic mechanism. Can J Physiol Pharmacol 2003;81:920-7.

20. Spiller RC. Role of nerves in enteric infection. Gut 2002;51:759-62.

21. Collins SM. Altered neuromuscular function in the inflamed bowel. In: Kirsner J, ed. Inflammatory Bowel Disease, 5th edn. Philadelphia:WB Saunders, 2000.

22. Fiorucci S, Mencarelli A, Palazzetti B, et al. Proteinase-activated receptor 2 is an anti-inflammatory signal for colonic lamina propria lymphocytes in a mouse model of colitis. Proc Natl Acad Sci USA 2001;98:13936-41.

23. Vergnolle N, Bunnett NW, Sharkey KA, et al. Proteinase-activated receptor-2 and hyperalgesia: A novel pain pathway. Nat Med 2001;7:821-6.

24. Coelho AM, Vergnolle N, Guiard B, Fioramonti J, Bueno L. Proteinases and proteinase-activated receptor 2: A possible role to promote visceral hyperalgesia in rats. Gastroenterology 2002;122:1035-47.

25. Barbara G, Cottrell G, Grady EF, et al. Expression and release of mast cell tryptase in irritable bowel syndrome (IBS). Gastroenterology 2002;122:A276. (Abst)

26. Asfaha S, Brussee V, Chapman K, Zochodne DW, Vergnolle N. Proteinase-activated receptor-1 agonists attenuate nociception in response to noxious stimuli. Br J Pharmacol 2002;135:1101-6.

27. Buresi MC, Hollenberg MD, Macnaughton WK. Activation of protease-activated receptor-1 (PAR-1) inhibits neurally evoked chloride secretion in the mouse colon. Can J Gastroenterol 2003;17(Suppl A):A30. (Abst)

28. Green BT, Bunnett NW, Kulkarni-Narla A, Steinhoff M, Brown DR. Intestinal type-2 proteinase-activated receptors: Expression in opioid-sensitive secretomotor neural circuits that mediate epithelial transport. J Pharmacol Exp Ther 2000;295:410-6. 


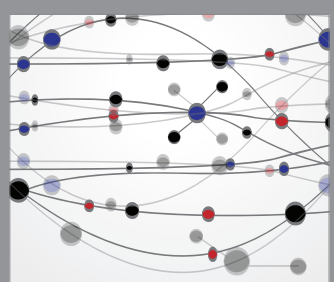

The Scientific World Journal
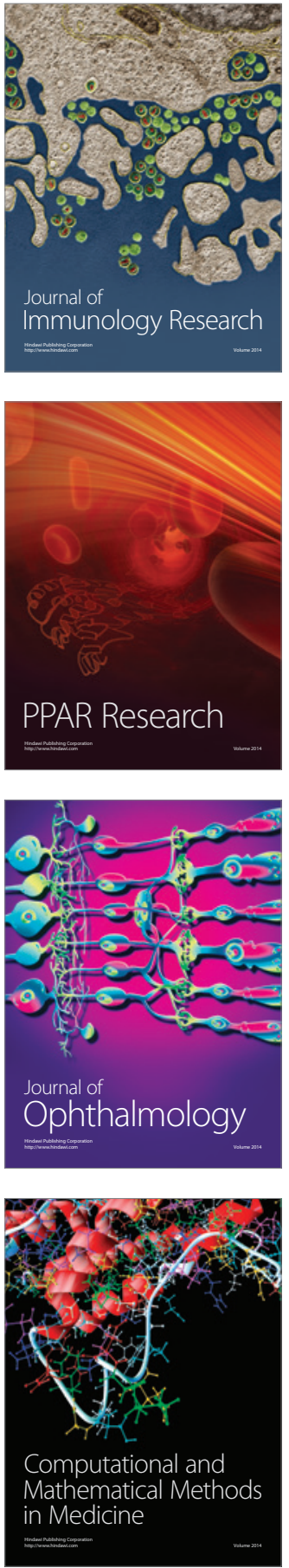

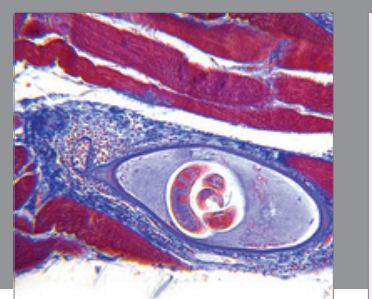

Gastroenterology Research and Practice

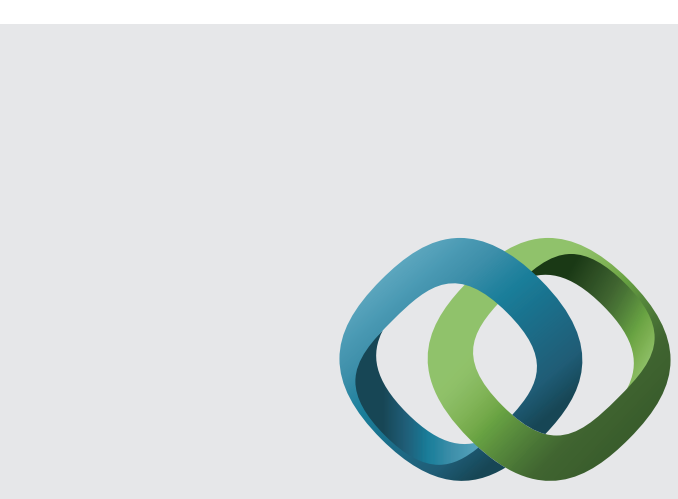

\section{Hindawi}

Submit your manuscripts at

http://www.hindawi.com
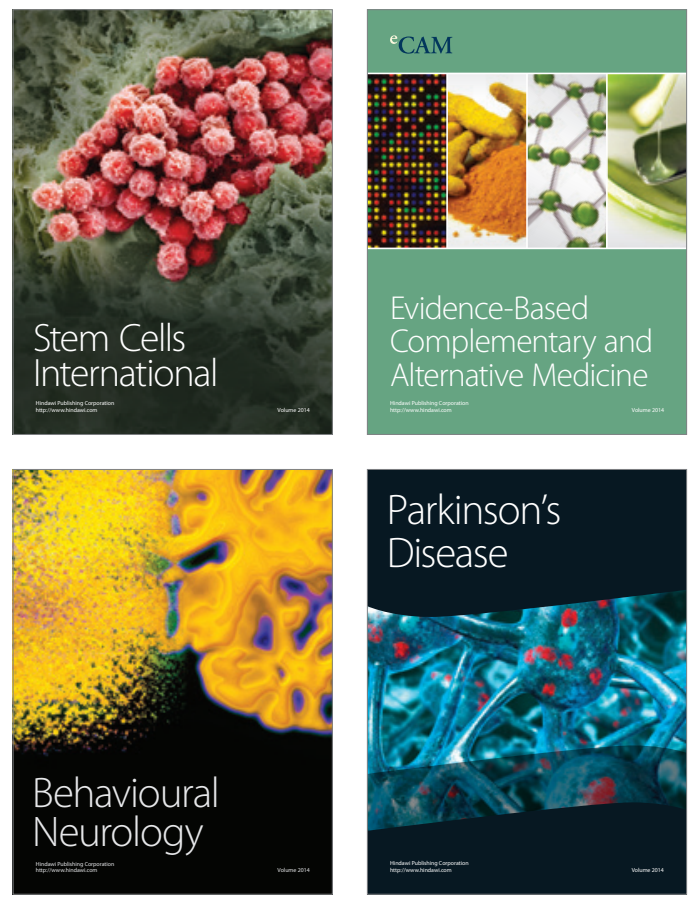
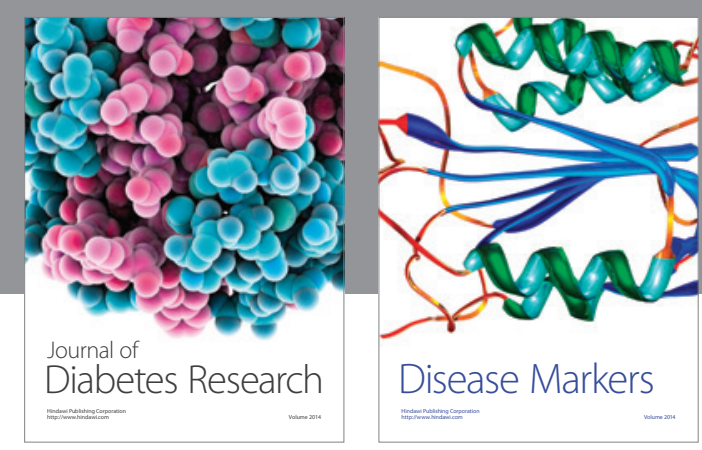

Disease Markers
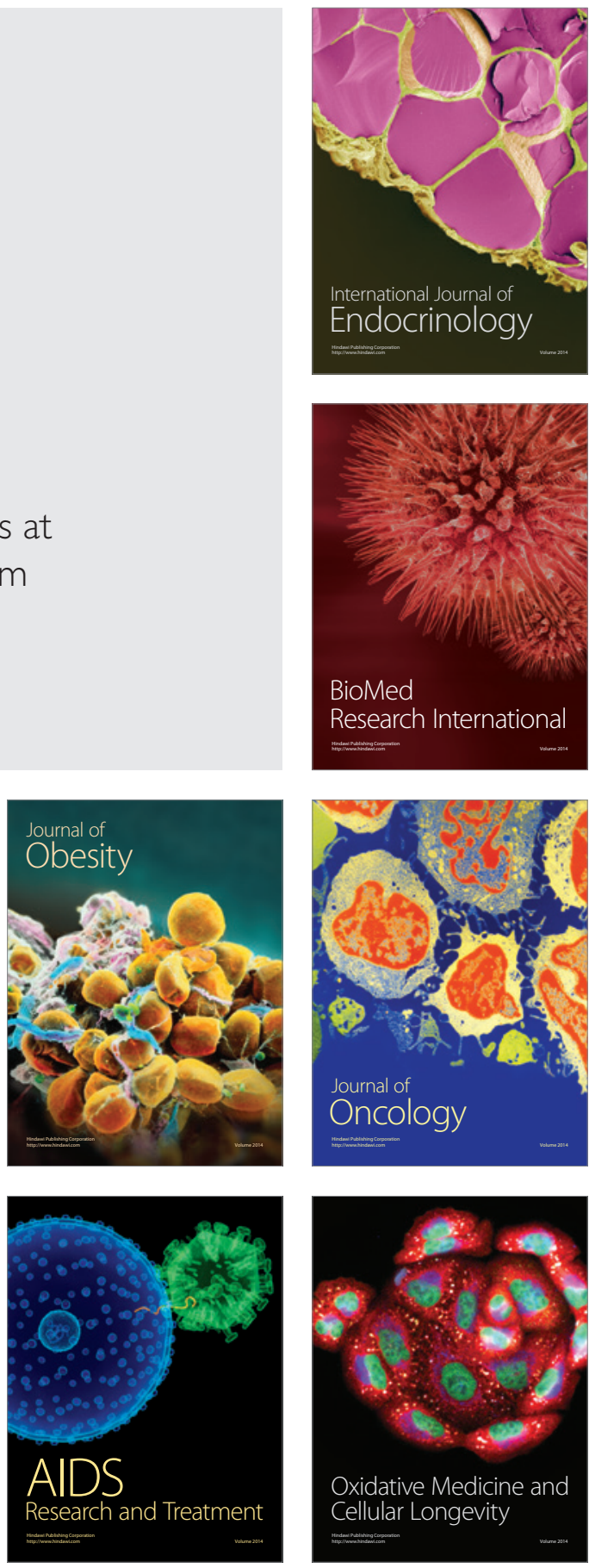